tested by Dr. Grant were of the 19-nor-17 $\alpha$-ethynyl configuration.

These findings enlarge the case for replacing the present oral contraceptives by others equally effective but having less dangerous and unpleasant side-effects. A promising development in this respect is the use of very small amounts of a progestogen such as chlormadinone acetate continually administered without added oestrogen and without suppressing ovulation. ${ }^{4}$ The case for low-dose progestogens is by no means established. They have a number of disadvantages of their own, but these begin to appear less formidable than those of the present oestrogen-progestogen mixtures.

\section{Varieties of Hyperparathyroidism}

Among the variety of disorders to which the parathyroid glands are subject is a syndrome coming to be known as tertiary hyperparathyroidism. This week in a paper at page 395 of the B.M.f. Mr. D. R. Davies, Professor C. E. Dent, and Dr. L. Watson establish the syndrome on a firm foundation. In their first 200 cases of primary hyperparathyroidism proved at operation the authors found 12 patients with parathyroid adenomata which probably developed on the basis of longstanding hyperplasia due to malabsorption or chronic renal glomerular failure. They accept the term "tertiary hyperparathyroidism," first suggested by Walter St. Goar ${ }^{1}$ to describe patients who develop parathyroid adenomata causing hypercalcaemia on top of reactive or secondary parathyroid hyperplasia.

As in primary hyperparathyroidism, women are more liable to the tertiary condition than men. The ages of the patients ranged from 28 to 72 years. More cases were associated with malabsorption syndromes than with chronic renal failure. The diseases concerned were gluten-sensitive enteropathy (6 cases); postgastrectomy osteomalacia (3 cases); and adult-presenting "vitamin-D-resistant" osteomalacia, polycystic kidneys, and prolonged renal glomerular failure of unknown cause (1 case each). Tertiary hyperparathyroidism should be suspected in any patient with longstanding malabsorption or renal failure who develops hypercalcaemia. In some instances the hypercalcaemia is observed during treatment with vitamin $\mathrm{D}$, but persists after this is withdrawn. When total plasma calcium levels are only marginally raised, estimation of the ionized calcium may give useful confirmation. In three-quarters of the patients bone $x$-rays or biopsies showed signs of osteomalacia, and in a similar number there was evidence of increased parathyroid action on bone-namely, osteitis fibrosa cystica. Thus it appears that tertiary hyperparathyroidism, like the primary variety, can occur with or without osteitis fibrosa cystica. While it might be argued that some patients with tertiary hyperparathyroidism were suffering from primary hyperparathyroidism which was missed initially, this possibility seems unlikely,

\footnotetext{
Case Records of Massachusetts General Hospital, New Engl. F. Med., 1963, 268, 943.

- Brit. med. F., 1968, 3, 3.

- Albright, F., and Reifenstein, E. C., The Parathyroid Glands and Metabolic Bone Disease, 1948. London.

- Lloyd, H. M., Medicine (Baltimore), 1968, 47, 53.

s Dent, C. E., Brit. med. F., 1962, 2, 1495.

- Potts, J. T., Jr., Aurbach, G. D., and Sherwood, L. M., Recent Progr. Hormone Res., 1966, 22, 101.

' Hodgkinson, A., Clin. Sci., 1963, 25, 231.
}

since the evolution of the syndrome was observed in four of these authors' patients, who had typical secondary hyperplasia when first seen and developed hypercalcaemia while under observation which was cured by removal of a parathyroid adenoma. As in all other disorders of calcium metabolism the role of calcitonin ${ }^{2}$ needs to be defined.

Secondary hyperparathyroidism is a well-recognized entity defined by F. Albright and E. C. Reifenstein ${ }^{3}$ as " a condition when more parathyroid hormone is manufactured than is normal but where this hormone is needed for some compensatory purpose." It can develop in response to any longmaintained hypocalcaemic stimulus such as malabsorption or chronic renal failure. Hyperplasia of all four parathyroids is usually present, and plasma calcium levels are low or normal but never raised, this depending on the extent to which the parathyroids are able to compensate for the hypocalcaemia. The bones show evidence of the previous hypocalcaemiarickets or osteomalacia as well as osteitis fibrosa cystica.

Primary hyperparathyroidism is not a rare disease and may be recognized more frequently when radioimmunoassays of parathyroid hormone become readily available. The condition usually results from a single adenoma but less often may be due to multiple adenomata, diffuse hyperplasia of all four glands, or to a parathyroid carcinoma. All patients have raised total plasma calcium or ionized calcium at some stage in the disease: a raised plasma calcium is still the single most important diagnostic criterion. Most patients present with either renal calculi or with overt bone disease. An analysis of Dent's patients by $H$. M. Lloyd ${ }^{4}$ produced evidence for two main types of parathyroid tumour, one growing rapidly, highly active, and causing overt bone disease, and the other growing slowly, of low activity, and causing kidney stones. It was originally suggested ${ }^{5}$ that these two types of parathyroid disease were due to secretion of different parathyroid hormones, but recent work ${ }^{6}$ has provided no evidence for the existence of two biologically distinct hormones. Primary hyperparathyroidism in all its forms must therefore be accepted as being due to excessive secretion of one parathyroid hormone, though it is conceded that modifying factors such as an increased absorption of dietary calcium : may prevent the development of overt bone disease in some patients with renal calculi despite high circulating levels of parathyroid hormone.

The concept of primary, secondary, and tertiary hyperparathyroidism has an important bearing on treatment. Both the primary and tertiary forms require surgical treatment to remove an adenoma unless renal failure is too advanced to allow operation, when haemodialysis can sometimes be helpful. Secondary hyperparathyroidism is improved by treatment with vitamin $\mathrm{D}$, which corrects the hypocalcaemia, removes the stimulus to the parathyroids, and allows the bone disease to heal. After removal of the adenoma in tertiary hyperparathyroidism, treatment with vitamin D may sometimes be required to prevent hypocalcaemia.

Dent and his colleagues also suggest that other cases of primary hyperparathyroidism might turn out to be examples of the tertiary state, resulting from longstanding parathyroid hyperplasia in response to hereditary or other factors as yet unknown. They provide a list of a wide variety of associated conditions found in their patients including relapsing pancreatitis, pulmonary tuberculosis, thyrotoxicosis, and rheumatoid arthritis. While these are probably sometimes chance associations, their theory could be tested by searching for evidence of secondary hyperparathyroidism by plasma alkaline phosphatase, bone radiographs and biopsies, and 
parathyroid gland studies at necropsy in patients with these diseases.

Tertiary hyperparathyroidism provides an opportunity to study the process of tumour formation in man, for the prolonged hypocalcaemic stimulus leads to hyperplasia, adenoma, and possibly to carcinoma. The situation is analagous to that occurring in other endocrine glands in which prolonged physiological stimuli eventually culminate in the development of benign and malignant tumours.

\section{Commonwealth Medical Association}

Delegates from 12 national medical associations and observers from nine more attended the recent meeting of the Council of the Commonwealth Medical Association in Canberra. In addition there were observers from several other areas in the Commonwealth where no national associations yet exist. Much of the credit for this fine muster is due to the Commonwealth Foundation in London, which generously provided funds towards the costs of those who came. The excellent arrangements and the warm hospitality of the host Australian Medical Association were beyond praise.

As the report of the proceedings at page 427 shows, the matters discussed served to stress the bonds that link doctors in all countries and in Commonwealth countries in particular. An application for membership by the Rhodesian Medical Association was agreed to unanimously. In accepting that its task should be "mainly advisory, co-ordinating, and motivating " the Council summed up the C.M.A.'s principal function. It carries this out through discussion and the exchange of information and ideas at its biennial meetings; by concerted action, as on this occasion in pressing for common standards for higher qualifications ; and by the visits of its travelling fellows to the more isolated medical associations. And between times there is correspondence between friends.

This may all sound quite modest, but the goodwill and the practical help given through the C.M.A. cement the links already existing between its member associations.

\section{Early Exit}

Failure to come down with a degree after attending a university used to be a private occasion of sorrow or relief. But now that the State pays for such a high proportion of university education in some way or other it is concerned to know what return it gets for its money. Consequently the University Grants Committee has periodically carried out surveys of the entrances and exits that undergraduate students make, looked into the reasons for them, and now in a report ${ }^{1}$ published last week compared the figures for different universities.

The inquiry concerns students who should have graduated in 1966, but it covers those who took an extra year to do so in 1967 and follows into 1968 those who then failed. The 'Enquiry into Student Progress, 1968, University Grants Committee,
1968. H.M.S.O. 27s. 6d. net. percentage of all students in this group $(35,386)$ who failed at some point in the course was 13.3. In medicine it was lower-namely, $8.8 \%$ of 2,060 students. Medicine was also notable for the relatively low loss due to academic reasonsabout two-thirds of those failing - and high loss for unspecified reasons. A roughly comparable inquiry in 1954 showed that $10.7 \%$ of medical students then failed.

The present report shows some differences in the medical failure rate at different universities. Sheffield had the highest rate of $21.5 \%$ representing 14 students, and Birmingham the next highest with $16.3 \%$ (16 students). Lowest was the Welsh National School of Medicine with $1.5 \%$ (one student). The Scottish universities were round about the average, as were London and most of the English universities. Owing to the small numbers considerable fluctuations of a chance nature are to be expected, and no doubt the variations from year to year must be considerable, so that this particular league table, though it may prompt a certain amount of speculation, cannot be taken very seriously. Failure in the final examinations seems to be rare, for the great majority of those who fall by the wayside do so by the end of the fourth year, the peak being at the end of the second year, when the clinical period looms ahead.

On the whole the figures suggest that selection procedures for entrance to medical schools are fairly efficient, and since there was a slight fall in the proportion dropping out between $1954(10.7 \%)$ and $1966-7(8.8 \%)$ they may have improved. It is possible too that medical students are more apt to stay the course because they feel a more absorbing purpose in their studies than do some of those in other faculties, who are surprisingly often found to have graduated with still no clear objective in mind. These are perhaps destined to fill what the report calls " the pool of qualified manpower." But whether universities should be springs of learning or taps to fill a pool is causing some thought at present.

\section{Leucocyte Alkaline Phosphatase and Hodgkin's Disease}

The fact that the cytoplasmic granules of polymorphonuclear leucocytes contain alkaline phosphatase was discovered over 20 years ago. In 1955 L. S. Kaplow ${ }^{1}$ showed that a histochemical technique could be adapted to give a semiquantitative estimate of the variation from normal in the amount of this enzyme in the leucocyte granules by using a scoring method. Since then the technique has been more widely applied and modifications have been introduced. Today a description of the technique is to be found in standard textbooks of haematology, and many laboratories include it in their routine methods. The first application was found to be in distinguishing between true chronic myeloid leukaemia and leukaemoid reactions in the blood. In chronic myeloid leukaemia the polymorph alkaline phosphatase was found to be much diminished or even absent altogether. In the leukaemoid reactions due to infections or occurring in

\footnotetext{
Kaplow, L. S., Blood, 1955, 10, 1023.

${ }^{2}$ Hayhoe, F. G. J., and Quaglino, D., Brit. F. Haemat., 1958, 4, 375.

$s$ Bennett, J. M., Nathanson, L., and Rutenburg, A. M., Arch. intern. Med., 1968, 121, 338.

- Rutenburg, A. M., Rosales, C. L., and Bennett, J. M., \}. Lab. clin. Med. 1965. 65. 698.
} 